\title{
Reducing Fumigant Application Rates and Soil Emissions with Plastic Mulch Technology ${ }^{1}$
}

\author{
J. W. Noling ${ }^{2}$
}

Fumigants such as methyl bromide, chloropicrin, metam, and 1,3-Dichloropropene have been used in combination with plastic mulch row covers since the early 1960s for broad spectrum, soilborne pest and disease control. Federal label restrictions for use of methyl bromide and other fumigants now require the installation of plastic mulch covering immediately following application. Use of agricultural plastic films (tarps) to cover the treated field after fumigation has been a common practice to reduce the fumigant emission and to minimize worker exposure to the fumigants. During the recent federal re-registration of soil fumigants, the U.S. Environmental Protection Agency (U.S. EPA) established a new set of regulations requiring a suite of complementary mitigation measures to protect handlers, re-entry workers, and bystanders from risks resulting from exposure to the soil fumigants. Among the new requirements is the need for a buffer zone between treated and untreated sites to allow airborne fumigant residues to disperse before reaching bystanders. EPA is also granting "buffer zone credits," which reduce buffer distances, to encourage fumigant users to employ practices that reduce emissions, such as with the use of high-barrier tarps. EPA, however, will only recognize use of specific high-barrier metalized, virtually impermeable (VIF), or totally impermeable (TIF) mulch films that meet EPA approved emission reductions to qualify for these buffer zone reducing credits.

With the new fumigant regulations and rising cost of crop production, including fumigants, it would be desirable to reduce the standard use rate of soil fumigants, particularly where the new fumigant labels impose more stringent buffer zone restrictions (near schools, clinics, prisons) and where fumigant shortage or use caps further restrict possible allocation and use.

\section{Plastic Mulch Bed Covers}

The most commonly used plastic mulches in Florida are black and white polyethylene (PE) mulches typically in the range of 0.6 to 1.4 mil thick. Many different colors, thicknesses, and widths of these embossed PE plastic mulches are available for agricultural use. In general, the advantages of plastic mulch include: 1) thermal regulation of soil temperature; 2) weed suppression; 3 ) increasing the effectiveness of soil applied pesticides; 4) maintenance of bed shape, architecture, and providing drainage; 5) barrier protection of fruit from soil pathogens; 6) minimizes root pruning from tillage operations for weed control; 7) minimizes the evaporative loss of water from soil; and 8) reduces leaching of fertilizers from the root zone of plants. In general, the plastic mulch layer protects crops from environmental extremes and impact, and serves to accelerate plant growth and increase crop yields.

In addition to the horticultural advantages, plastic mulches also serve to delay the volatilization of fumigant gases from soil, and reduce emissions into the atmosphere. In practical reality, however, the PE mulches in common use today

1. This document is ENY046, one of a series of the Entomology and Nematology Department, Florida Cooperative Extension Service, Institute of Food and Agricultural Sciences, University of Florida. Original publication date October 2001. Reviewed December 2012. Revised March 2013. Visit the EDIS website at http://edis.ifas.ufl.edu.

2. J. W. Noling, professor, Entomology and Nematology Department, Citrus Research and Education Center, Cooperative Extension Service, Institute of Food and Agricultural Sciences, University of Florida, Lake Alfred, FL 33850. 
in Florida actually provide little direct physical barrier to the diffusion of most fumigants through the mulch. The condensation of water on the under surface of the film and the resultant increased moisture content within surface soil appears to be actually more important for slowing the volatilization of these fumigants from soil than the mulch itself. The water seal that forms on the soil surface acts as a diffusion barrier because diffusion of a gas through water is much less and slower than diffusion through open soil pores. Similarly, beds that are moist and tightly compressed are much more resistant to fumigant diffusion than beds that are dry and only loosely compacted or pressed.

\section{Emissions of Methyl Bromide from Agricultural Fields}

In recent years, many different field studies have been conducted to obtain information on soil fumigant emissions from bare and mulch-covered soil following field application. Much of this research appears to show that as much as 20 to $90 \%$ of a fumigant like methyl bromide applied to a given field can ultimately out-gas through the PE plastic mulch cover and into the air after soil fumigation. Many different chemical, soil, and environmental factors interact to cause the wide variation of reported emission losses from soil with any of the currently used fumigant compounds. In general, the rate at which a specific fumigant volatilizes from soil under typical conditions is initially high following application and then decreases with time, such that after 7 to 14 days post application, little remains in soil (Figure1).

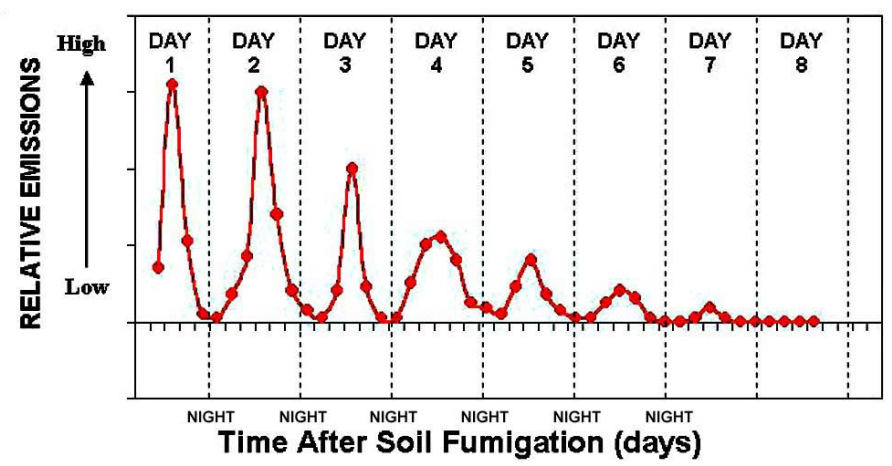

Figure 1. Generalized representation of the relative emissions of a soilapplied fumigant volatilizing through a plastic-polyethylene mulch cover with time after initial soil fumigation. Data is plotted only to show general decline in emissions with time, and highest daily rates of emission occurring midday and lowest emissions at night. Besides temperature, other soil and environmental conditions can greatly modify fumigant emissions from soil.

After application, volatilization continues as long as the fumigant remains in the soil and a concentration-difference exists under the plastic and the lower air of the field. With methyl bromide, a large proportion of the methyl bromide applied volatilizes from soil within the first 24 to 48 hours following application. Most other fumigants with lower vapor pressure require considerably longer to diffuse and completely dissipate from soil. Since temperature has such a direct effect, the highest levels of fumigant out-gassing typically occur during the middle of the day, when air temperatures are highest. Outgassing levels are lowest at night, when air temperatures are coolest. The use of higherbarrier, gas-impermeable mulches may make it possible to reduce fumigant application rates by helping to contain the fumigant longer within the soil and reduce overall emissions into the atmosphere.

\section{Mulch Permeability}

The permeability (the ability to pass through) of a plastic mulch to any soil fumigant is technically and quantitatively expressed as a "mass transfer coefficient" (MTC), which is dependent only upon the properties of the film (thickness, density, chemical composition), the properties of the fumigant, and physical conditions of the environment (such as temperature and humidity).

Regardless of composition, thicker mulches are generally less permeable to a soil fumigant than are thin mulches (Figure 2). In most cases, practical and cost efficiency considerations prevent the use of thicker PE mulches for enhanced containment of a fumigant in soil.

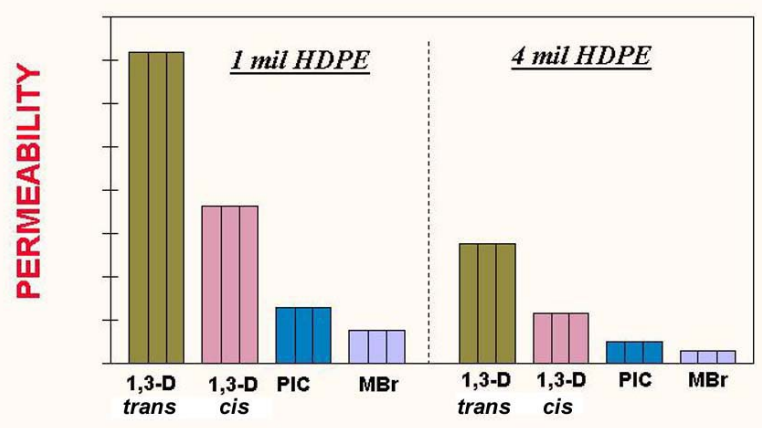

Figure 2. Permeability of methyl bromide (Mebr), Chloropicrin (Plc), and two isomers of 1,3-Dichloropropene (Telone") through highdensity polyethylene (HDPE) plastic mulch of two thicknesses. Taller bars indicate higher permeability.

Among the different commercially available plastic mulch films (Table 1), some films provide a better diffusion barrier to certain fumigants than others (Figures 2, 4). PE films are the group with the highest permeability. Even within the PE group, the high-density polyethylene (HDPE) films can be differentially (more or less) permeable to a variety of different fumigants (Figure 2). Metalized films follow as a group with barrier properties characterized as only moderately 
permeable. The VIF films are considered in a group with very low permeability, allowing very little of a fumigant gas to pass through it, and as the name implies, are virtually impermeable. TIF films belong to a group where measured permeability is typically defined as being negligible (Figure $3)$.

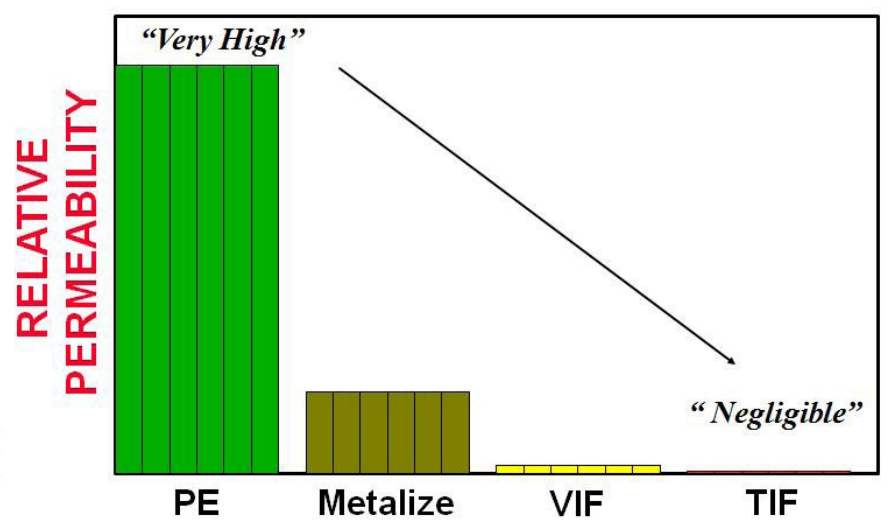

Figure 3. Relative permeability of fumigant gases through polyethylene (PE), metalize, virtually impermeable (VIF) and totally impermeable (TIF) plastic mulch films. Taller bars indicate higher permeability.

These VIF and TIF mulches are typically multi-layer films composed of barrier polymers such as ethylene vinyl alcohol (EVOH) or polyamide (nylon) sandwiched between other polymer layers (typically PE) that keep the barrier polymers from swelling. Compared to PE mulch films, VIF and TIF films are oftentimes over 20,000 times less permeable to a variety of fumigant compounds (Figure 4).

The permeability of the different mulch films (Table 1) to different fumigants can vary considerably, providing a reasonable barrier for one fumigant but not another (Figure 4). For example, some of the high-barrier, high-density polyethylene mulches provide some resistance to methyl bromide and chloropicrin but were shown to offer less resistance to 1,3-D (Telone ${ }^{\oplus}$ ) diffusion (Figure 2). MITC, the active ingredient of metam sodium $\left(\right.$ Vapam $\left.^{\circledR}\right)$ and metam potassium $\left(\mathrm{KPam}^{\circledast}\right)$, is even more diffusive than Telone $^{\oplus}$ through a variety of different mulch film types compared to methyl bromide, methyl iodide (IOM), or chloropicrin (Figure 4).

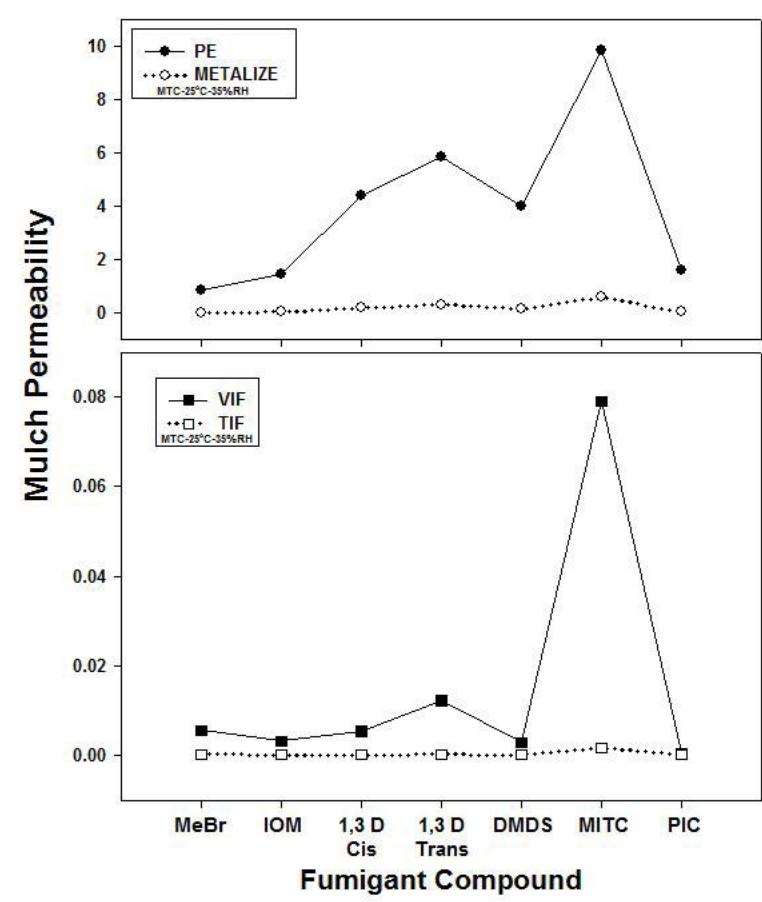

Figure 4. Permeability of methyl bromide (Mebr), iodomethane (IOD), two isomers of 1,3-Dichloropropene (Telone $\left.{ }^{\circ}\right)$, dimethyl disulfide (DMDS) (Paladin ${ }^{\circ}$, methyl isothiocyanate (MITC)( Vapam ', KPam *), and Chloropicrin (PIC), through polyethylene (PE), metalized, virtually impermeable (VIF) and totally impermeable (TIF) plastic mulch films. Higher values indicate higher permeability. Note differences in $Y$ axis scales between panels and mulch film types representing very significant orders of magnitude differences in permeability.

In Florida mulch trials, monitoring of soil gas concentration and persistence was able to differentiate, relative to low density PE, the general retentiveness of 12 different gasimpermeable plastic mulches to the soil fumigant methyl iodide (iodomethane) (Figure 5). With this fumigant and others that were tested, the low-density PE mulch film was characterized as the least retentive of the mulches evaluated, with the fumigant generally dissipating completely from soil within 3 to 4 days. All of the different metalized and VIF mulch films produced higher soil air concentrations ( $\mathrm{ppm}$ ) over a longer period of time ( $>7$ days) than soil air concentrations produced under low-density PE. The benefits of using the high-barrier metalized and VIF films during fumigation has been documented in this as in many other studies to enhance fumigant efficacy by retaining fumigants in the soil for longer periods of time. 


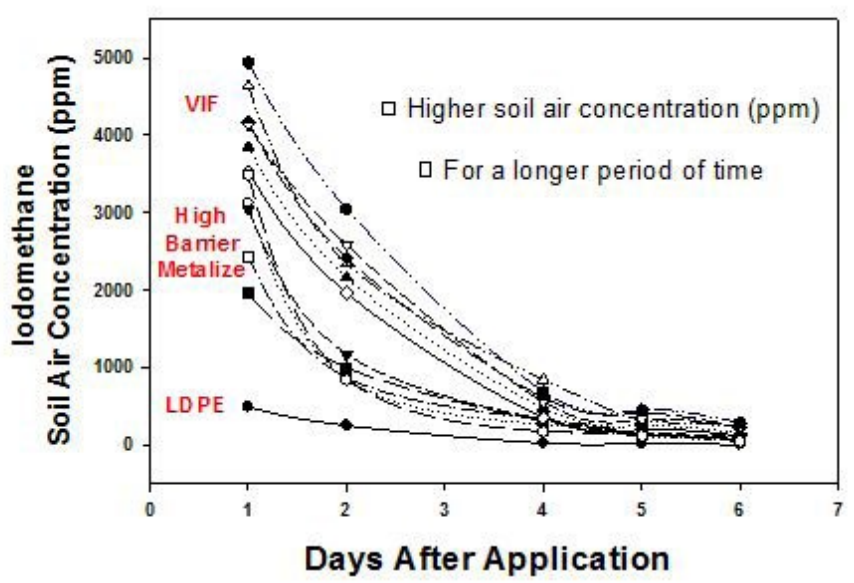

Figure 5. Soil air concentrations of iodomethane (methyl iodide) under different low-density polyethylene (LDPE), metalized, and virtually impermeable (VIF) plastic mulch films monitored over a seven-day period. Note higher soil air concentration over time within response curves for the VIF and metalized mulch films compared to LDPE.

Research on the use of various types of high-barrier mulches to reduce soil application rates and emissions of methyl bromide has also been conducted in many different locations nationally and around the world. For example, use of virtually impermeable plastic mulches (VIF) has proved to be a simple and effective strategy to reduce soil emissions of not only methyl bromide but of other fumigant gases as well. It is clear from the research that has been conducted with VIF and TIF that fumigant use rates can be substantially reduced without serious consequence to pest control efficacy or crop yield response. The results of most of these field studies show that fumigant application rates can be reduced by 20 to as much as $40 \%$ through the use of virtually impermeable or the more gas-tight TIF mulch films at the time of application. These high-barrier mulches cannot always be used without problems, however.

\section{Potential Problems with High- Barrier Mulches}

Historically, VIF and TIF mulches have suffered from high cost and from other problems involving tensile strength. They were oftentimes slow to properly install and were subject to tearing (zippering) during machine application in the field. Most of these problems have been resolved. However, other problems that can and do frequently occur involve delays in fumigant dissipation from soil and a phytotoxic response to young seedlings and transplants transferred to soils containing phytotoxic soil residues of the fumigant. For example, fumigants containing 1,3-dicloropropene (an active ingredient in several fumigant products, including Telone II, Telone ${ }^{\circ}$ C-35, and PicClor $60^{\circ}$ ) can have a long plant-back interval if a high-barrier VIF or TIF mulch film is used, particularly if the soil remains wet or cool after application. In this scenario, the fumigant is trapped under an impermeable barrier, preventing its volatilization and escape from the soil. The more efficient containment of gases below the mulch suggests that soil air concentrations of the fumigants should be monitored and that plantings may have to be delayed to ensure that soil residues have dissipated and plant injury will not occur. At present the detection of any fumigant in soil air suggests a potentially serious problem with an appropriate delay in planting to avoid issues of plant damage and mortality.

The specific high-barrier mulch film products and names of the principal manufacturers or their U.S. distributors are listed in Table 1. Additional updated information regarding U.S. EPA-approved plastic mulch films or tarps for soil fumigant uses can be found at: http://www.epa.gov/ pesticides/reregistration/soil_fumigants/ 
Table 1. Selected manufacturers or vendors of a variety of polyethylene mulch films (PE), metalized films, virtually impermeable films (VIF) and totally impermeable plastic mulch films. Films represent different thicknesses (mil), colors, embossing, and barrier layers.

\begin{tabular}{|c|c|c|}
\hline \multicolumn{3}{|l|}{ Polyethylene Films (PE): } \\
\hline AEP Sun Film High Barrier & 1.0 mil, clear polyethylene & AEP Inc. \\
\hline Cadillac HDPE & 1.25 mil, clear & Cadillac Products Packaging Co. \\
\hline Canslit Embossed HDPE & 0.6 mil, black & Canslit Inc./Imaflex Inc. \\
\hline Canslit Embossed LDPE & 1.25 mil, black & Canslit Inc./Imaflex Inc. \\
\hline Pliant Embossed LDPE & 1.25 mil, embossed LDPE & Pliant Corp \\
\hline \multicolumn{3}{|l|}{ Metalized Films: } \\
\hline Canslit Metalized & 1.25 mil, black/silver & Canslit Inc./Imaflex Inc. \\
\hline Canslit Metalized & 1.25 mil, white/silver & Canslit Inc./Imaflex Inc. \\
\hline Pliant Metalized & 1.25 mil, black/silver & Pliant Corp \\
\hline \multicolumn{3}{|l|}{ Virtually Impermeable Films (VIF): } \\
\hline Cadillac VIF & 1.25 mil, black & Cadillac Products Packaging Co. \\
\hline Can-Block VIF & $0.8 \mathrm{mil}$, black & Canslit Inc./Imaflex Inc. \\
\hline FilmTech VIF & 1.25 mil, black & FilmTech Corp. \\
\hline Ginegar Ozgard & 1.25 mil, black & Ginegar Plastic Products, Ltd. \\
\hline Ginegar VIF & 1.25 mil, embossed black & Ginegar Plastic Products, Ltd. \\
\hline Guardian Olefinas VIF & 1.2 mil, embossed black & Guardian Agroplastics Olefinas USA \\
\hline MidSouth VIF & 1.25 mil, embossed black & Mid South Extrusion \\
\hline Pliant Blockade Black & 1.25 mil, black & Pliant Corp \\
\hline Pliant Blockade White & 1.25 mil, white/black & Pliant Corp \\
\hline \multicolumn{3}{|l|}{ Totally Impermeable Films (TIF): } \\
\hline AEP-One & EVOH barrier, 1.0 mil, clear & AEP Inc. \\
\hline Berry EVOH-High Barrier & EVOH barrier, black & Berry Plastics \\
\hline Berry High Barrier w/improved toughness & EVOH barrier, black & Berry Plastics \\
\hline Berry EVOH-Supreme Barrier & EVOH barrier, black & Berry Plastics \\
\hline Dow SARANEX A & black & Dow Chemical Co. \\
\hline Dow SARANEX B & black & Dow Chemical Co. \\
\hline Klerks/HyPlast TIF & clear & Klerk's Plastic/HyPlast \\
\hline Raven TIF VaporSafe & 1.0 mil, EVOH barrier, clear & Raven Industries Inc. \\
\hline Raven TIF VaporSafe & 1.4 mil, EVOH barrier, black & Raven Industries Inc. \\
\hline
\end{tabular}

